\title{
Oceanographic and climatic factors differentially affect reproduction performance of Antarctic skuas
}

\author{
Steffen Hahn ${ }^{1,4}{ }^{*}$, Klaus Reinhardt ${ }^{2}$, Markus S. Ritz ${ }^{1}$, Tim Janicke ${ }^{1}$, Diego Montalti ${ }^{3}$, \\ Hans-Ulrich Peter ${ }^{1}$ \\ ${ }^{1}$ Institute of Ecology, Friedrich-Schiller-University Jena, Dornburger Strasse 159, 07743 Jena, Germany \\ ${ }^{2}$ Department of Animal \& Plant Sciences, University of Sheffield, Sheffield S10 2TN, UK \\ ${ }^{3}$ Instituto Antartico Argentino, Cerrito 1248, C1010AAZ Buenos Aires, Argentina \\ ${ }^{4}$ Department of Plant-Animal Interactions, Centre for Limnology, Netherlands Institute of Ecology (NIOO-KNAW), \\ PO Box 1299, 3600 BG Maarssen, The Netherlands
}

\begin{abstract}
We studied how environmental conditions affect reproduction in sympatric skua species that differ in their reliance on marine resources: the exclusively marine foraging south polar skua Catharacta maccormicki, the terrestrially foraging brown skua C. antarctica lonnbergi and mixed species pairs with an intermediate diet. Egg size, clutch asymmetry and hatching dates varied between species and years without consistent patterns. In the south polar skuas, 12 to $38 \%$ of the variation in these parameters was explained by sea surface temperature, sea ice cover and local weather. In mixed species pairs and brown skuas, the influence of environmental factors on variation in clutch asymmetry and hatching date decreased to $10-29 \%$, and no effect on egg size was found. Annual variation in offspring growth performance also differed between species with variable growth in chicks of south polar skuas and mixed species pairs, and almost uniform growth in brown skuas. Additionally, the dependency on oceanographic and climatic factors, especially local wind conditions, decreased from south polar skuas to brown skua chicks. Consistent in all species, offspring were more sensitive to environmental conditions during early stages; during the late chick stage ( $>33 \mathrm{~d}$ ) chick growth was almost independent of environmental conditions. The net breeding success could not be predicted by any environmental factor in any skua species, suggesting it may not be a sensitive indicator of environmental conditions. Hence, the sensitivity of skuas to environmental conditions varied between species, with south polar skuas being more sensitive than brown skuas, and between breeding periods, with the egg parameters being more susceptible to oceanographic conditions. However, during offspring development, local climatic conditions became more important. We conclude that future climate change in the Maritime Antarctic will affect reproduction of skuas more strongly through changes in sea ice cover and sea surface temperature (and the resulting alterations to the marine food web) than through local weather conditions.
\end{abstract}

KEY WORDS: Maritime Antarctic - Sea surface temperature - Sea ice cover - Catharacta spp. Breeding parameter $\cdot$ Chick growth $\cdot$ Life history

\section{INTRODUCTION}

The climate of the western Antarctic Peninsula region has undergone profound changes in the last decades, such as a 2 to $3^{\circ} \mathrm{C}$ increase in mean air temperatures over the last $50 \mathrm{yr}$, an earlier retreat of winter sea ice, and an increased frequency of extreme weather events (see e.g Smith \& Stammerjohn 2001, Vaughan et al. 2003). These changes can have opposing effects on polar seabirds. For example, while reduced sea ice cover generally facilitates foraging of marine surface feeders, decreased winter sea ice is also associated with lower krill densities in summer (Siegel \& Loeb 1995, Loeb et al. 1997). Krill Euphausia 
spp.) comprise the key resource for almost all higherorder predators in the Antarctic, either representing the main prey for penguins, fishes and whales, or indirectly affecting top predators such as seals and skuas that prey on krill-consuming species. Because the Antarctic food web is comparatively simple (Hempel \& Kerry 1990), environmental changes affecting lower food chain levels can also rapidly influence reproduction and population dynamics of top predators (Fraser \& Hofmann 2003, Weimerskirch et al. 2003).

In studies of polar seabirds, oceanographic factors like sea ice cover and sea surface temperatures have been used as proxies for food accessibility and availability, as they indicate open water and areas of enhanced primary production (e.g. Ainley et al. 1998, Barbraud \& Weimerskirch 2001). Furthermore, local weather conditions in summer influence the breeding success of seabirds directly via their effects on offspring growth (Busser et al. 2004).

Oceanographic and local weather conditions in the Maritime Antarctic vary remarkably between years (Smith \& Stammerjohn 2001). Therefore, reliable predictions have been largely lacking on how particular environmental factors affect different episodes of reproduction and, hence, population dynamics of the respective species.

In our study we analysed the effect of oceanographic and climatic factors on reproduction of Antarctic skuas Catharacta spp., which are important top predators in the Antarctic marine ecosystem (Young 1994, Phillips et al. 2004). In the South Shetland Islands, western Antarctic Peninsula region, the distribution ranges of the closely related south polar skua $C$. maccormicki and brown skua $C$. antarctica lonnbergi overlap and they breed sympatrically (reviewed by Ritz et al. 2006). Additionally, both species regularly form mixed pairs comprising a south polar skua male and a brown skua female (e.g. Hahn et al. 2003). Within the area of sympatry, the skua species occupy different ecological niches separated by foraging behaviour and foraging areas. Whereas the diet of south polar skuas comprises 90 to $95 \%$ marine food, mainly pelagic fishes, brown skuas feed mainly on seabirds, their eggs and chicks, e.g. penguins, petrels and storm-petrels (Reinhardt 1997). This species-specific foraging behaviour is reflected in the diet provided to offspring of mixed species pairs with 45 to $80 \%$ marine and 18 to $50 \%$ terrestrial food (Pietz 1987, Reinhardt 1997).

The sympatric breeding but different foraging of skuas in the South Shetlands provided the unique opportunity of identifying species-specific responses to the same set of environmental factors. We used egg dimensions and chick hatching date as indicators of conditions at the beginning of the breeding period (e.g. Hiom et al. 1991) and indices of chick growth variation for the characterisation of late-season effects (Ritz et al. 2005). Additionally we recorded the total breeding success as an overall measure of annual breeding output.

As the skua species should have similar requirements for nest initiation and incubation in spring, we expected the annual variation in egg dimensions and hatching dates to be similar across skua species. Later in the breeding season, offspring development should depend on parental foraging strategy and, thus, vary between species. In south polar skuas, offspring growth was expected to be influenced by both marine and local weather conditions, because breeding adults have to fly larger distances between nest and offshore foraging areas (Pietz 1986). This leaves offspring exposed to potentially adverse weather, and provisioning largely depends on the accessibility and availability of marine food. In contrast, chick growth of brown skuas should depend merely on local weather conditions because of their terrestrial food.

Overall breeding success is unlikely to be affected by a single environmental factor if different environmental factors influence reproductive performance period specifically. However, we expected that in accordance with their different feeding habits, reproduction of south polar skuas and brown skuas would depend on oceanographic and local climatic factors, respectively. This could be confirmed by the intermediate position of the mixed species pairs.

\section{MATERIALS AND METHODS}

Study site and population. The study sites were 2 neighbouring ice-free areas, Fildes Peninsula and Potter Peninsula, on King George Island $\left(62^{\circ} \mathrm{S}, 58^{\circ} \mathrm{W}\right)$ in the Maritime Antarctic. King George Island belongs to the South Shetland Island group. This group is separated from the Antarctic Peninsula by the approximately $100 \mathrm{~km}$ wide Bransfield Strait. The climate on the island is characterised by high precipitation

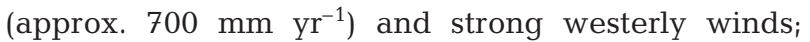
storms with maximum wind speeds $>100 \mathrm{~km} \mathrm{~h}^{-1}$ are typical. Mean summer temperatures (January and February) and winter temperatures (July and August) are 1.5 and $-6.5^{\circ} \mathrm{C}$, respectively; the snowmelt normally starts at the end of October. During the winter months, the adjacent sea is covered with fast sea ice until October or November, with a high interannual variability of ice cover extent and duration.

We analysed data of the breeding performance on Antarctic skuas Catharacta spp. on Fildes Peninsula and Potter Peninsula in the austral summers of 1983-84 to 2003-04. The breeding grounds are approx. $15 \mathrm{~km}$ apart; exchanges of individuals between the sites 
occur regularly (S. Hahn et al. pers. obs.). The skua breeding populations on Fildes Peninsula (Potter Peninsula) consists, on average, of 170 (50) pairs of south polar skuas C. maccormicki (SPS), 70 (30) pairs of brown skuas C. antarctica lonnbergi (BS), and 25 (10) mixed species pairs (MSP). All individuals were identified to species level by plumage coloration and body size differences. MSP consist of SPS males and BS females (Hahn et al. 2003). SPS, BS and MSP are henceforth referred to as 'skua forms'. The data set includes the breeding seasons of 1984, 1985, 1987, 1988 (Fildes Peninsula) and 1994 to 1995 and 1999 to 2004 (Potter Peninsula). The year refers to the time of chick fledging, e.g. 1984 denote the austral summer of 1983 to 1984. Skuas breeding in the Antarctic are migratory birds, which only attend their breeding sites during the reproduction period. Hence, the abiotic winter conditions at the breeding areas should influence the annual breeding performance of the birds indirectly, e.g. by different dates of snowmelt or sea ice break-up. In our study we focused on 2 different periods of skua reproduction: the pre-incubation period from October to November, and the chick-rearing period from January to March. The incubation period (December) was not considered in the analysis, because we assumed that neither egg parameters nor chick growth were influenced by this period.

Breeding parameters. Egg measurements and hatching date: Clutch size, egg dimensions (length and breadth, $\pm 0.1 \mathrm{~mm}$ ) and egg mass ( $\pm 1 \mathrm{~g}$ ) were measured for each nest. Egg size was calculated as egg size $\left(\mathrm{cm}^{3}\right)$ $=0.00048 \times$ length $\times$ breadth $^{2}$ (after Coulson 1963). We incorporated only first-egg data into the analysis of egg size. If clutches contained 2 eggs, we calculated clutch asymmetry (CA) as size of second egg divided by size of first egg (Catry \& Furness 1997). Hatching dates were either observed directly or calculated using hatching date-egg density relationships: 50 and $90 \%$ errors of estimation were 1.4 and $<4 \mathrm{~d}$, respectively (formulas for BS + MSP: Hahn \& Peter 2003, SPS: M. S. Ritz unpubl. data). We considered only the hatching date of the first chick per clutch as the second chick invariably hatches 1 to 3 d later. Years containing only 1 data point were excluded (BS in 1984, MSP in 1988). Hatching dates are given as days from 1 December (e.g. 1 January = Day 32) and were square-root transformed to conform to normal distribution. For all skua forms and breeding parameters, we calculated a long-term mean over all study years and the annual deviations as the difference between annual and long-term mean.

Chick growth performance: Skua chicks were weighed at irregular intervals during their growth period; to avoid handling effects the minimum interval length was $4 \mathrm{~d}$. For each skua form, a growth curve was calculated for body mass as $A /\{1+\exp [k \times(\mathrm{x}-t 0)]\}$, where $A=$ asymptotic size, $k=$ growth constant and $t 0=$ age at the inflection point of the sigmoid model. We included all chicks, irrespective of hatching order and survival to fledging. The goodness of fit of the models was $r^{2}=0.96(d f=1125)$ for SPS, $r^{2}=0.95(d f=613)$ for MSP and $r^{2}=0.94(\mathrm{df}=1409)$ for BS. Individual chick growth performance was expressed as the proportional deviation from the predicted body mass at a given age. An average value was calculated if more than 2 data points per chick were available. The growth variability between skua forms and between years was quantified by an average value for each chick for the complete growth period from the age of $10 \mathrm{~d}$ to fledging or death, called the 'entire stage model'. Furthermore, we repeated the analyses of chick growth performances for the chick stages 'early' (Days 10 to 21), 'middle' (Days 22 to 33) and 'late' (Days 34 to fledging). All growth data of chicks younger than $10 \mathrm{~d}$ were excluded because of lack of variance homogeneity.

Breeding success: For each skua form we calculated an annual average breeding success as the number of chicks fledged per nest.

Environmental factors. We calculated the impact of maritime factors that may indirectly affect skua reproduction via food (namely regional and local sea ice conditions) as proxies for accessibility of maritime food, and sea surface temperatures as a proxy for food availability (Ainley et al. 1998, Prézèlin et al. 2004). Direct effects on skua offspring and adults were measured by local weather conditions, characterised by air temperature, precipitation and wind speed.

Sea ice cover (SIC): We used the denoted means of sea ice extent at $60^{\circ} \mathrm{W}$ from October to March of each breeding season as a measurement of the regional sea ice cover (available at www.natice.noaa.gov and www. antcrc.utas.edu.au/ jacka/seaice.html). Because there were no data available for the exact area at $58^{\circ} \mathrm{W}$, we calculated a monthly anomaly value of northern sea ice extent assuming related sea ice conditions at 60 and $58^{\circ}$. This monthly sea ice anomaly is given as An60 = mean ice extent $\left(60^{\circ} \mathrm{W}\right.$ from 1983 to 2004$)$ - actual ice extent $\left(60^{\circ} \mathrm{W}\right)$, e.g. a month with less-than-average sea ice cover has a negative anomaly value.

Local ice break-up: We characterised the local ice break-up at the adjacent Bransfield Strait $\left(60^{\circ} \mathrm{W}\right.$, $62.7^{\circ} \mathrm{S}$ to $63.8^{\circ} \mathrm{S}$ ) as the first month of each austral summer when $50 \%$ of the strait was free of ice (sea ice edge $\left.>63.2^{\circ} \mathrm{S}\right)$.

Sea surface temperature (SST): We calculated a monthly average of sea surface temperatures at $62^{\circ} \mathrm{S}$ from the area of $62^{\circ} \mathrm{S}, 57^{\circ} \mathrm{W}$ to $62^{\circ} \mathrm{S}, 59^{\circ} \mathrm{W}$ (available at http://iridl.ldeo.columbia.edu/SOURCES/.NOAA/ .NCDC/.ERSST/.version2/.SST/). SST ranged from $-0.32 \pm 0.12^{\circ} \mathrm{C}$ in early spring to $1.25 \pm 0.27^{\circ} \mathrm{C}$ during the chick-rearing period. 
Local weather (air temperature and precipitation): We used published data of monthly mean air temperatures $\left({ }^{\circ} \mathrm{C}\right.$ ) and precipitation (mm) from 1984 to 2004 measured at the Russian Scientific Base Bellingshausen, Fildes Peninsula (available at www.aari.nw.ru/ projects/Antarctic/default_en.asp).

Wind speed: For a smoothed average we used the monthly means $\left(\mathrm{m} \mathrm{s}^{-1}\right)$ calculated from 4 measurements per day at Bellingshausen Station, Fildes Peninsula, from 1984 to 2004. Additionally, we used the 9:00 h daily measurement at the Argentinean base, Jubany (1987 to 2004: data provided by Servicio Meteorologico Nacional, Argentina), Potter Peninsula, as a more variable and 'event-based' measure of wind speed. Furthermore, we counted the monthly number of days with a wind speed $>15 \mathrm{~m} \mathrm{~s}^{-1}$ from the Jubany data set.

Statistical methods. We compared the breeding parameters of skuas using ANOVA with skua form and year as factors. Additionally we analysed the coefficients of variation (CV) and correlation coefficients of breeding parameters to determine magnitude and direction of deviations from the long-term mean.

The impact of environmental factors on skua reproduction was analysed by multinomial linear regressions with a backward iteration procedure to exclude non-significant factors.

For the pre-incubation period (October to November), we sought to explain egg size, clutch asymmetry and hatching date by the following environmental factors: sea ice cover (SIC) at $60^{\circ} \mathrm{W}$, local ice break-up and mean sea surface temperature at $62^{\circ} \mathrm{S}$ (SST), mean air temperatures (Temp), mean precipitation (Prec) and mean wind speed (Wind).

We analysed the influence of abiotic factors on chick growth for both the entire growth period ('entire stage model') and separately for the 3 chick stages (see above). In the entire stage regression model, we used the mean values of chick growth performance as dependent variable and the means of regional sea ice cover anomaly (SIC), local ice break-up, mean sea surface temperature (SST), average air temperatures (Temp), average wind speed (Wind) and precipitation (Prec) for the complete chick period from January to March as independent variables.

The models for the chick stages included chick growth data for 7 yr (1994 and 1999 to 2004) and the environmental factors SIC and local ice break-up, SST, monthly means of temperature, precipitation, wind speed and the number of days with wind speed $>15 \mathrm{~m} \mathrm{~s}^{-1}$.

Although some of the tested abiotic factors varied in a collinear way we decided to focus on original factors rather than calculating artificial factor complexes (sensu Graham 2003). In the pre-incubation period,
SIC was correlated with local ice break-up $(r=0.82$, $\mathrm{p}=0.001)$ and mean wind speed was correlated with air temperature $(r=0.69, p=0.01)$ as well as with precipitation $(r=0.63, p=0.02$, all $n=13)$. In the chickrearing period, average air temperature and SST were correlated (entire stage model, $r=0.60, p=0.03, n=$ $13)$, whereas in the fine-tuned stage models precipitation correlated with the number of stormy days, indicating that storms in summer are almost always accompanied by precipitation (SPS: $\mathrm{r}=0.97, \mathrm{n}=5$, MSP: $\mathrm{r}=$ 0.84, $\mathrm{n}=7$, BS: $\mathrm{r}=0.86, \mathrm{n}=7$, all $\mathrm{p}<0.03$ ).

\section{RESULTS}

\section{Egg parameters and hatching}

Egg size of SPS differed significantly between study years $\left(F_{9,328}=6.06, \mathrm{p}=0.001\right)$ caused by differences between 1993 and 2004 (small egg sizes) and 1994, 2001 and 2002 (years with large eggs) (post hoc Tamhane, $p<0.05$, Table 1 ). In contrast, egg sizes of BS and MSP did not differ significantly between years (BS: $F_{11,260}=1.21, \mathrm{p}=0.28$; MSP: $F_{11,106}=0.44, \mathrm{p}=0.94$ ， Table 1). The annual coefficient of variation for egg size did not differ consistently between the skua forms (RM ANOVA: $F_{2,11}=0.93, \mathrm{p}=0.41$ ), and consequently there was no correlation (Spearman's rank correlation $R_{S}$ ) between the skua forms (SPS and MSP $r_{S}=0.59, p=$ $0.07, \mathrm{n}=10$; SPS and BS $\mathrm{r}_{\mathrm{S}}=-0.07, \mathrm{p}=0.84, \mathrm{n}=10$; MSP and BS $r_{S}=-0.01, p=0.97, n=12$ ). These results indicate that egg sizes varied differently in the skua forms, even in MSP and BS where females belonged to the same species. Environmental factors explained $12 \%$ of egg size variation in SPS, with $11 \%$ from maritime sources: high SST and early ice break-up positively influenced egg size, whereas SIC had an adverse effect (Fig. 1A, Table 2). Local weather conditions were much less important for egg size. However, none of our environmental factors explained variation in egg size of BS or MSP (Fig. 1A, Table 2).

Clutch asymmetry varied significantly between years $\left(F_{11,561}=21.04, \mathrm{p}=0.001\right)$ and there was also an interactive effect of skua form $\times$ year $\left(F_{18,561}=2.98, \mathrm{p}=\right.$ 0.001). SPS laid more uniform clutches (0.992) than BS (0.975) or MSP $(0.977)$, Tamhane post hoc $t$-test: SPS and BS: $p=0.001$; SPS and MSP: $p=0.077$; BS and MSP: $\mathrm{p}=0.98$ (Table 1). Moreover, clutch asymmetry was correlated between SPS and BS $(r=0.74, p=0.04$, $\mathrm{n}=8)$, and even stronger between BS and MSP ( $\mathrm{r}=$ $0.90, p=0.001, n=10$ ). Clutch asymmetry was not related between SPS and MSP $(r=0.63, p=0.07, n=9)$.

Environmental factors explained between $23 \%$ (BS) and $38 \%$ (SPS) of the variation in clutch asymmetry in all skua forms, with a prominent role of marine factors 
(Fig. 1B, Table 2). Generally, in years with low SIC and early ice break-up females laid more even clutches, irrespective of skua form. In contrast, SST was negatively related to clutch asymmetry for SPS, but positively related for BS and MSP. Local weather conditions explained 3.6, 0.4 and $2.3 \%$ of variation in clutch asymmetry in SPS, MSP and BS, respectively (Fig. 1B).

The mean hatching date varied across years and skua forms (year: $F_{12,612}=$ $15.85, \mathrm{p}=0.001$; skua forms: $F_{2,612}=$ $4.43, \mathrm{p}=0.012$; interaction year $\times$ forms: $F_{20,612}=2.43, \mathrm{p}=0.001 ;$ GLM (general linear model) Type I sum of squares; see Table 1 for annual mean hatching dates). Annual mean hatching dates were not correlated between the skua forms (SPS and BS r $=0.42, \mathrm{p}=0.23, \mathrm{n}=$ 10; SPS and MSP chicks $\mathrm{r}=0.60, \mathrm{p}=$ $0.07, \mathrm{n}=10 ; \mathrm{BS}$ and MSP $\mathrm{r}=0.59, \mathrm{p}=$ $0.056, \mathrm{n}=11$ ). Chicks of both SPS and MSP hatched within a shorter period $\left(\mathrm{CV}_{\mathrm{MSP}}=0.21 \pm 0.12, \mathrm{CV}_{\mathrm{SPS}}=0.23 \pm\right.$ 0.083 , paired $t$-test: $t_{9}=-0.52, \mathrm{p}=0.62$ ) than chicks from BS pairs $(0.31 \pm 0.08)$ (paired $t$-test of CVs BS - MSP: $t_{10}=3.82$, $\mathrm{p}=0.003 ;$ BS - SPS: $t_{9}=3.51, \mathrm{p}=0.007$ ). For both BS and SPS, chicks hatched earlier from larger eggs (SPS: $r=-0.33$, $\mathrm{p}=0.001, \mathrm{n}=238 ; \mathrm{BS}: \mathrm{r}=-0.29, \mathrm{p}=$ $0.001, \mathrm{n}=199)$, but not for MSP $(\mathrm{r}=$ $-0.12, \mathrm{p}=0.29, \mathrm{n}=84$ ).

Environmental factors explained $36 \%$ of hatching date variation in SPS, but only 14 and $10 \%$ in MSP and BS, respectively (Fig. 1C, Table 2). In particular, SPS chicks hatched earlier in years with high SST, little sea ice cover and early ice break-up. Less precipitation also favoured early hatching of SPS offspring. BS hatching dates were significantly delayed by extended sea ice cover, low temperatures, high wind speed and less precipitation. For MSP, late sea ice break-up and low precipitation delayed hatching (Fig. 1C, Table 2).

\section{Chick growth and breeding success}

Chick growth variation differed between the skua forms: whereas deviation from the mean growth trajectory

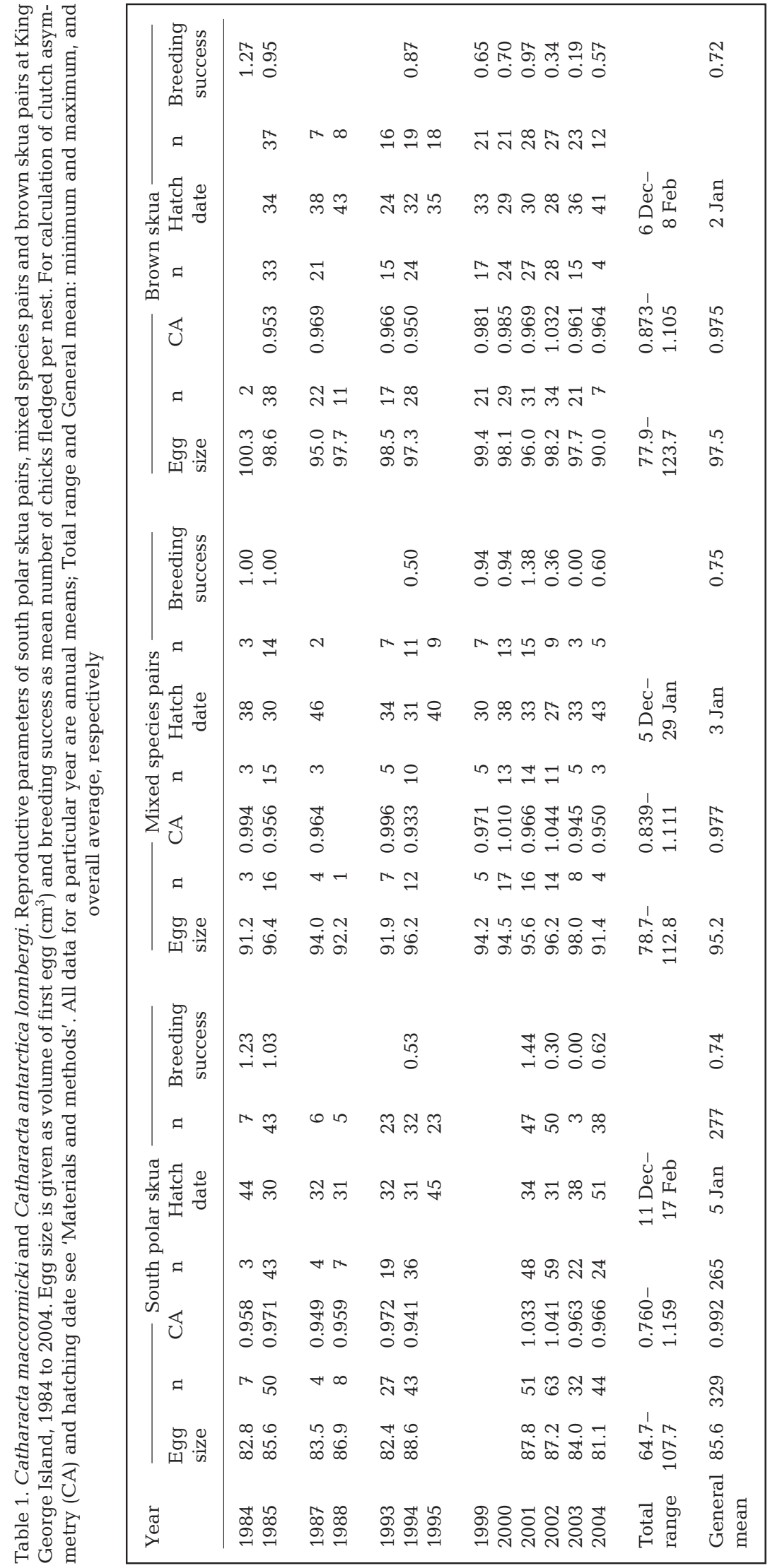



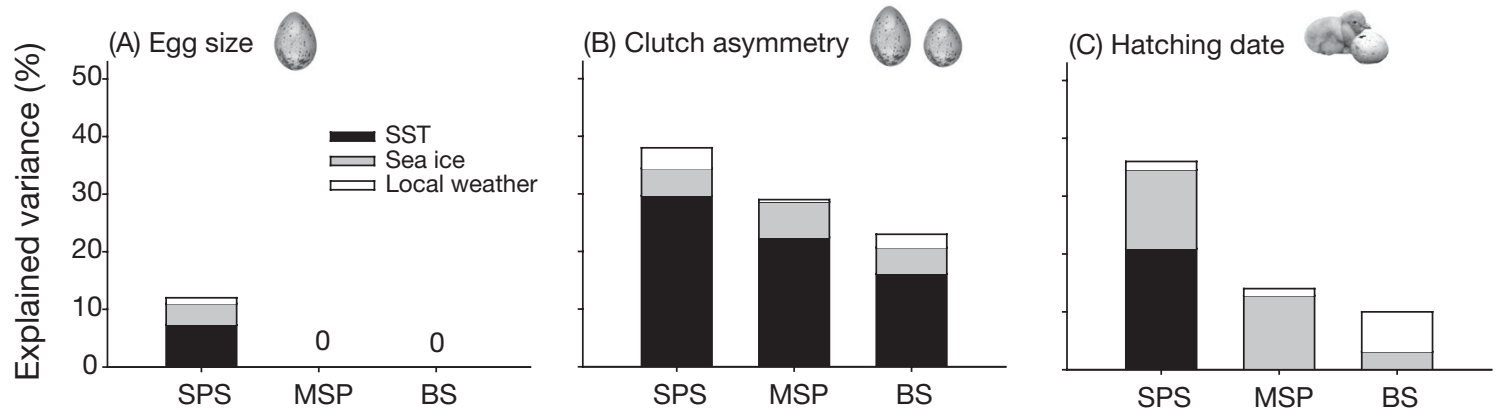

Fig. 1. Catharacta maccormicki and Catharacta antarctica lonnbergi. Proportion of variance explained by environmental factors in (A) egg size, (B) clutch asymmetry and (C) hatching date of Antarctic skuas. Each factor expressed as proportional absolute value of that factor's coefficient of total explained variance. SPS: south polar skua; MSP: mixed species pairs; BS: brown skua; SST: sea surface temperature; Sea ice: local and regional sea ice cover: Local weather: local conditions of air temperature, precipitation and wind speed

Table 2. Catharacta maccormicki and Catharacta antarctica lonnbergi. Results of multinomial linear regressions, comparing influence of environmental factors on egg size, clutch asymmetry and hatching date of south polar skuas (SPS), mixed species pairs (MSP) and brown skuas (BS) at King George Island during pre-incubation periods from 1984 to 2004. SST: sea surface temperature; SIC: sea ice cover extent at $60^{\circ} \mathrm{W}$; Ice break-up: first month when Bransfield Strait was $50 \%$ free of sea ice; Temp: monthly mean of temperature; Prec: precipita-

tion. $\mathrm{R}^{2}$ and $\mathrm{B}$ : quality and slope of the multinomial regression, respectively

\begin{tabular}{|c|c|c|c|c|c|c|c|c|c|}
\hline & $\mathrm{R}^{2}$ & $F$ & $\mathrm{p}$ & df1 & $\mathrm{df} 2$ & Variable & B & $t$ & $\mathrm{p}$ \\
\hline \multicolumn{10}{|l|}{ Egg size } \\
\hline \multirow[t]{5}{*}{ SPS } & 0.12 & 9.16 & 0.001 & 5 & 328 & SST & 212.97 & 2.52 & 0.01 \\
\hline & & & & & & SIC & 54.00 & 4.41 & 0.001 \\
\hline & & & & & & Ice break-up & -54.92 & -4.89 & 0.001 \\
\hline & & & & & & Temp & 15.34 & 2.52 & 0.01 \\
\hline & & & & & & Wind & 13.79 & 2.62 & 0.01 \\
\hline MSP & 0.09 & 0.77 & 0.38 & 1 & 105 & - & & & \\
\hline BS & 0.07 & 1.23 & 0.27 & 1 & 260 & - & & & \\
\hline \multicolumn{10}{|c|}{ Clutch asymmetry } \\
\hline \multirow[t]{3}{*}{ SPS } & 0.38 & 53.94 & 0.001 & 3 & 264 & SST & -0.25 & -5.79 & 0.001 \\
\hline & & & & & & SIC & -0.04 & -8.59 & 0.001 \\
\hline & & & & & & Temp & 0.03 & 6.77 & 0.001 \\
\hline \multirow[t]{3}{*}{ MSP } & 0.29 & 11.37 & 0.001 & 3 & 86 & SST & 0.11 & 2.17 & 0.033 \\
\hline & & & & & & SIC & -0.03 & -4.21 & 0.001 \\
\hline & & & & & & Prec & 0.002 & 5.23 & 0.001 \\
\hline \multirow[t]{3}{*}{ BS } & 0.23 & 21.01 & 0.001 & 3 & 218 & SST & 0.07 & 2.55 & 0.012 \\
\hline & & & & & & Ice break-up & -0.02 & -4.98 & 0.001 \\
\hline & & & & & & Prec & 0.01 & 7.83 & 0.001 \\
\hline \multicolumn{10}{|c|}{ Hatching date } \\
\hline \multirow[t]{5}{*}{ SPS } & 0.36 & 30.20 & 0.001 & 5 & 276 & SST & -37.27 & -2.57 & 0.011 \\
\hline & & & & & & SIC & -13.12 & -7.43 & 0.001 \\
\hline & & & & & & Ice break-up & 11.13 & 8.04 & 0.001 \\
\hline & & & & & & Prec & -0.42 & -5.50 & 0.001 \\
\hline & & & & & & Wind & 2.16 & 1.87 & 0.06 \\
\hline \multirow[t]{2}{*}{ MSP } & 0.14 & 7.88 & 0.001 & 2 & 97 & Ice break-up & 2.12 & 2.26 & 0.026 \\
\hline & & & & & & Prec & -0.20 & -3.57 & 0.001 \\
\hline \multirow[t]{4}{*}{ BS } & 0.10 & 6.31 & 0.001 & 4 & 236 & SIC & 2.93 & 3.09 & 0.002 \\
\hline & & & & & & Temp & -2.69 & -2.51 & 0.013 \\
\hline & & & & & & Prec & -0.24 & -3.49 & 0.001 \\
\hline & & & & & & Wind & 3.61 & 2.66 & 0.008 \\
\hline
\end{tabular}

differed between years in SPS $\left(F_{6,227}=\right.$ $13.48, \mathrm{p}=0.001)$ and in $\operatorname{MSP}\left(F_{8,104}=\right.$ $3.26, \mathrm{p}=0.002)$, BS chicks grew more uniformly without significant interannual differences $\left(F_{8,256}=1.54, \mathrm{p}=\right.$ 0.14 ; Table 3). The annual deviations of the skua forms were not correlated with each other (SPS and BS: $\mathrm{r}=-0.03$, $\mathrm{p}=0.96, \mathrm{n}=7$; SPS and MSP: $\mathrm{r}=0.32$, $\mathrm{p}=0.48, \mathrm{n}=7$; BS and MSP: $\mathrm{r}=0.55, \mathrm{p}=$ $0.13 ; \mathrm{n}=9$ ), indicating species-specific effects within a particular year. Chick growth differed between skua forms mainly in the early chick stage (Table 3), but these differences disappeared in the middle stage for BS and the late stage for MSP and SPS. In the late stage, only growth performances of BS and MSP chicks were related $(\mathrm{r}=$ $0.92, p=0.004, n=8$; all others $p>0.05$ ).

In the entire stage model, sea ice conditions and local weather explained 27 and $13 \%$ of variation in offspring growth in SPS and MSP, but none of the environmental factors contributed to chick growth variation in BS (Fig. 2A, Table 4). The decreasing model fit from SPS $\left(r^{2}=0.27\right)$ to MPS $\left(r^{2}=0.13\right)$ to BS $\left(\mathrm{r}^{2}=0.02\right)$ suggests a 2-fold larger influence of environmental factors on SPS than on MSP and almost nil on BS (Table 4). Chick growth for SPS and MSP was significantly delayed in years with extended sea ice, strong wind and precipitation (the latter for SPS only). Local temperatures and SST parameters did not contribute to variance in chick growth for any skua form (Fig. 2A). 
Table 3. Catharacta maccormicki and Catharacta antarctica lonnbergi. Statistical comparison of annual deviation from average mass growth trajectory of chicks from south polar skua pairs (SPS), from mixed species pairs (MSP) and from brown skua pairs (BS). Chick period was subdivided into early stage (10 to $21 \mathrm{~d})$, middle stage ( 22 to $33 \mathrm{~d}$ ) and late chick stage ( $>33 \mathrm{~d})$

\begin{tabular}{|lrlll|}
\hline \multicolumn{1}{|c}{ Chick stage } & $F$ & $\mathrm{p}$ & $\mathrm{df1}$ & $\mathrm{df2}$ \\
\hline SPS & & & & \\
$\quad$ Early & 14.94 & 0.001 & 5 & 160 \\
Middle & 4.83 & 0.001 & 5 & 154 \\
Late & 0.78 & 0.56 & 5 & 105 \\
& & & & \\
MSP & & & & \\
$\quad$ Early & 4.68 & 0.001 & 7 & 89 \\
Middle & 2.89 & 0.01 & 7 & 82 \\
Late & 1.80 & 0.10 & 7 & 76 \\
BS & & & & \\
Early & 2.02 & 0.04 & 8 & 216 \\
Middle & 0.64 & 0.72 & 7 & 187 \\
Late & 2.03 & 0.05 & 8 & 141 \\
\hline
\end{tabular}

In the stage-specific models, the model fit decreased from early, to middle, to late stage (Table 4). In the early stage, the number of days with strong wind negatively influenced chick growth of SPS and MSP, whereas high SST and high precipitation facilitated chick development in both skua forms. In BS, high precipitation delayed chick growth significantly (Fig. 2B, Table 4). In later stages, the proportion of growth variation explained by environmental factors decreased to $0-16 \%$ in the middle stage and $0-14 \%$ in the late stage. In SPS and MSP regional sea ice cover and stormy days negatively influenced chick development in the middle but not in the late stages (Fig. 2C, Table 4). For BS, no additional variation in chick growth was explained in the middle and late chick stage, indicating relative independence of chick growth from environmental factors.

The breeding success of SPS and MSP varied between years without any trend (SPS: $\mathrm{r}^{2}=0.27, F_{1,6}=$ 1.86, $\mathrm{p}=0.23$; MSP: $\mathrm{r}^{2}=0.14, F_{1,8}=1.15, \mathrm{p}=0.32$ ), but complete breeding failure occurred in 2003 (Table 1). In contrast, breeding success of BS declined throughout the study period (linear regression $r^{2}=0.60$, $\left.F_{1,8}=10.40, \mathrm{p}=0.015\right)$ at a rate of 0.034 chicks $\mathrm{yr}^{-1}$ $( \pm 0.011 \mathrm{SE})$, but breeding never failed completely. The annual breeding success of all skua forms was correlated (SPS - BS: $\mathrm{r}=0.88, \mathrm{p}=0.008, \mathrm{n}=7$; SPS - MSP: $\mathrm{r}=0.99, \mathrm{p}=0.001, \mathrm{n}=7$; BS - MSP: $\mathrm{r}=0.78, \mathrm{p}=0.014$, $\mathrm{n}=9$ ) indicating common factors influencing breeding success.

When skuas forms were analysed separately, breeding success of SPS and BS was not correlated with any environmental factors (SPS: $n=7, B S: n=9$, all $p>$ 0.05). For MSP, breeding success was negatively correlated with regional sea ice extent during the chickrearing period (MSP: $r=-0.72, p=0.03, n=9$ ). When the data were pooled and corrected for skua form, breeding success was positively correlated with ambient temperatures in the pre-incubation period (partial correlation: $\mathrm{r}=0.46, \mathrm{p}=0.02, \mathrm{df}=22$ ) and with mean wind speed during chick growth (partial correlation: $r=0.50, p=0.01, d f=22$ ). Regional sea ice cover during chick growth was negatively correlated with total breeding success (partial correlation: $\mathrm{r}=-0.59, \mathrm{p}=$ 0.002, df $=22$ ).

\section{DISCUSSION}

The climate of the maritime Antarctic has warmed recently, especially during winter (Smith \& Stammerjohn 2001), and has strongly influenced the marine
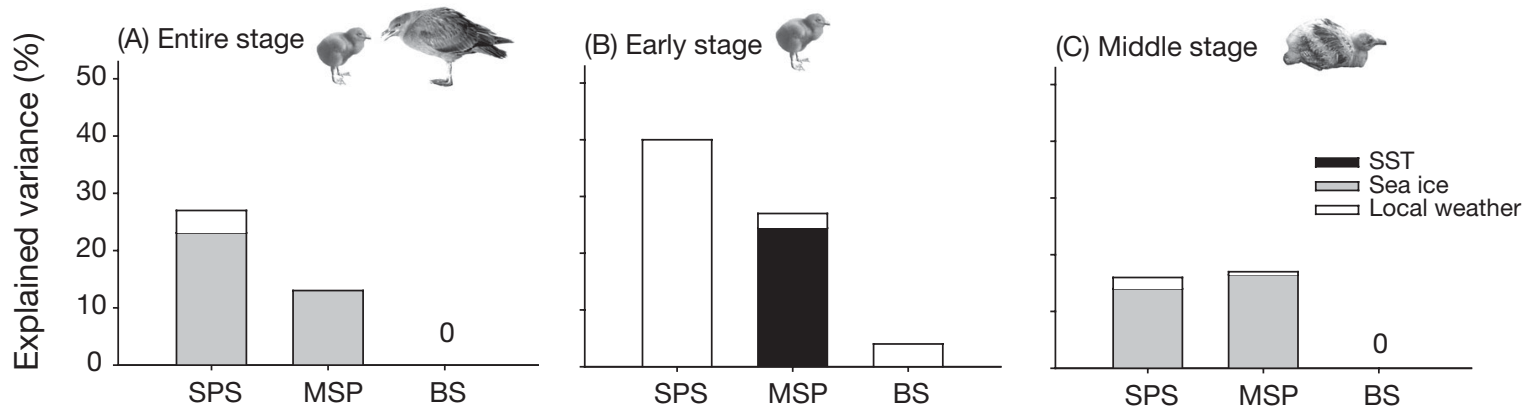

Fig. 2. Catharacta maccormicki and Catharacta antarctica lonnbergi. Proportion of variance in chick growth explained by environmental factors. (A) Entire stage model comprising entire chick growth period; (B) early stage model comprising data from 10 to $21 \mathrm{~d}$ old chicks; (C) middle stage model comprising data from 22 to $33 \mathrm{~d}$ old chicks. Each factor expressed as proportional absolute value of that factor's coefficient of total explained variance. SPS: south polar skua; MSP: mixed species pairs; BS: brown skua; SST: sea surface temperature; Sea ice: local and regional sea ice cover; Local weather: local air temperature, precipitation and wind speed 
Table 4. Catharacta maccormicki and Catharacta antarctica lonnbergi. Results of multinomial linear regressions, comparing influence of environmental factors on chick growth of south polar skuas (SPS), mixed species pairs (MSP) and brown skuas (BS). Entire stage model included data of chicks from $10 \mathrm{~d}$ old to fledgling compared with general environmental conditions; fine-tuned models were calculated for 3 chick stages (early, middle and late) with environmental conditions adjusted to stage. SIC: sea ice cover anomaly at $60^{\circ} \mathrm{W}$, Ice break-up: first month with $50 \%$ of Bransfield Strait free of sea ice; SST: sea surface temperature, Temp, Prec, Wind: means of temperatures, precipitation and wind speed, respectively; Wind $n>15$ : number of days with wind speed $>15 \mathrm{~m} \mathrm{~s}^{-1}$. $\mathrm{R}^{2}$ and $B$ : quality and the slope of the multinomial regression, respectively

\begin{tabular}{|c|c|c|c|c|c|c|c|c|c|}
\hline & $\mathrm{R}^{2}$ & $F$ & $\mathrm{p}$ & df1 & $\mathrm{df} 2$ & Variable & B & $t$ & $\mathrm{p}$ \\
\hline \multicolumn{10}{|c|}{ Entire stage model } \\
\hline \multirow[t]{4}{*}{ SPS } & 0.27 & 16.24 & 0.001 & 5 & 227 & $\mathrm{SIC}$ & -33.97 & -5.58 & 0.001 \\
\hline & & & & & & Ice break-up & 8.38 & 3.46 & 0.001 \\
\hline & & & & & & Prec & -0.40 & -2.59 & 0.01 \\
\hline & & & & & & Wind & -6.77 & -2.94 & 0.004 \\
\hline MSP & 0.13 & 15.67 & 0.001 & 1 & 104 & SIC & -25.67 & -3.96 & 0.001 \\
\hline BS & 0.02 & 2.14 & 0.12 & 2 & 256 & - & & & \\
\hline \multicolumn{10}{|c|}{ Fine-tuned models } \\
\hline \multicolumn{10}{|c|}{ Early chick stage } \\
\hline \multirow[t]{2}{*}{ SPS } & 0.40 & 37.20 & 0.001 & 2 & 112 & Prec & 0.85 & 2.59 & 0.01 \\
\hline & & & & & & Wind $\mathrm{n}>15$ & -14.98 & -8.58 & 0.001 \\
\hline \multirow[t]{2}{*}{ MSP } & 0.27 & 13.00 & 0.001 & 2 & 72 & $\mathrm{SST}$ & 38.41 & 4.86 & 0.001 \\
\hline & & & & & & Wind $\mathrm{n}>15$ & -4.04 & -2.06 & 0.043 \\
\hline BS & 0.04 & 3.53 & 0.03 & 2 & 174 & Prec & -0.23 & -2.41 & 0.017 \\
\hline \multicolumn{10}{|c|}{ Middle chick stage } \\
\hline \multirow[t]{3}{*}{ SPS } & 0.16 & 6.29 & 0.001 & 3 & 99 & SIC & -15.02 & -2.96 & 0.004 \\
\hline & & & & & & Prec & -0.15 & -2.07 & 0.04 \\
\hline & & & & & & Wind $\mathrm{n}>15$ & -1.64 & -2.36 & 0.02 \\
\hline \multirow[t]{2}{*}{ MSP } & 0.17 & 3.96 & 0.012 & 3 & 63 & SIC & -33.91 & -3.45 & 0.001 \\
\hline & & & & & & Prec & 0.584 & 2.50 & 0.015 \\
\hline BS & 0.004 & 0.59 & 0.44 & 1 & 135 & - & & & \\
\hline \multicolumn{10}{|c|}{ Late chick stage } \\
\hline SPS & 0.01 & 0.67 & 0.42 & 1 & 74 & - & & & \\
\hline MSP & 0.14 & 2.34 & 0.07 & 4 & 61 & - & & & \\
\hline BS & 0.03 & 3.44 & 0.07 & 1 & 120 & - & & & \\
\hline
\end{tabular}

the same sites (but with differing foraging habits), the reproduction of skuas showed (1) species-specific annual variations, (2) species-specific effects of environmental factors on reproduction, and (3) different sensitivity to environmental factors at different stages of the breeding cycle.

\section{Breeding parameters}

Egg formation is nutritionally and energetically costly to female birds (Robbins 1981). Therefore, egg size is a useful index of food availability and/or female body reserves during egg development (Hiom et al. 1991, Ratcliffe et al. 1998). Egg size in all skua forms varied annually by 4.2 to $7.7 \%$, with no correlation between the various forms, indicating that female condition (reflected by their ability to lay large eggs) differed between years due to variations in resource availability (e.g. in terms of body reserves or local food abundance). Additionally, the investigated factors affected first-egg size only in SPS. This species is very likely to use local marine food for first egg development, since $12 \%$ of its egg size variation was explained by oceanographic factors, whereby high SST and early local ice break-up favoured large first-eggs. Surprisingly, large eggs were also associated with extended regional sea ice cover, prob-

ecosystem from the lowest to the highest trophic levels. For example phytoplankton communities were affected by the lowered sea water salinity arising from melting glaciers (Moline et al. 2004). Likewise, speciesspecific changes in population size of penguins were caused by decreasing winter sea ice and food availability (Smith et al. 1999, Fraser \& Hofmann 2003). Thus, the impact of the current alterations in climatic conditions differed with respect to the focal species. The predictions of its effect (e.g. on reproduction success and population dynamics) highly depend on the relevant species sensitivity to a particular environmental factor (e.g. Guinet et al. 1998, Barbraud \& Weimerskirch 2001, Jenouvrier et al. 2003).

In our study we assessed the species-specific reproductive performance of Antarctic skuas and determined the effect of oceanographic and climatic factors on their breeding parameters. Although breeding at ably an indication of a link between winter ice cover and food availability in spring, as has been found to affect krill distribution in the region (Siegel 2000). In contrast, female BS and MSP developed at least their first egg unaffected by ambient conditions at the breeding site (none of the tested environmental factors explained egg size variations in both skua forms). Thus, these females either benefited from a continuously available and plentiful local resource (i.e. penguins) or employed (partly) a capital breeding strategy and synthesised eggs from resources accumulated elsewhere (Klaassen 2003).

A similar picture of a closer relation between female BS and MSP in comparison to SPS females was given by the analysis of clutch asymmetry as a proportional measure of size of the second egg. These findings were not unexpected, since females in BS and MSP associations belong to the same species and similar con- 
straints for egg development are very likely. However, the production of an equally sized second egg depended to a great extent on environmental conditions, which explained 23 to $38 \%$ of variance in clutch asymmetry across all skua forms. Therefore, females would seem to have used local resources for the production of their second egg (especially sources of marine origin, since oceanographic factors were of major importance: Fig. 1B).

Hatching dates varied greatly between years, ranging from the beginning of December until midFebruary. Taking a 28 to $31 \mathrm{~d}$ incubation period (Burton 1968), the laying period starts in November with BS laying first and SPS later in the season. Eggs of SPS and MSP hatched more synchronously than those of BS - probably a direct consequence of synchrony in arrival times. Assuming a similar selection pressure for early laying in Antarctic birds, as in northern hemisphere species (Price et al. 1988), the long laying/hatching period (>2 mo) suggests considerable variation in adult condition within each skua form. Likewise, we demonstrated a specific sensitivity to environmental factors: hatching for BS pairs was less influenced by environmental factors than that for MSP and SPS pairs, the latter being strongly affected by SST, followed by sea ice conditions, but with little effect of local weather conditions (Fig. 1C). High SST and little sea ice in the pre-breeding stage favoured early egg laying and hatching whereas low temperatures and a late ice break-up delayed hatching of the chicks.

Generally, SST had a marked influence in annual variation of breeding onset and egg size parameters in all skua forms, which might be explained via 2 pathways. First, higher SST in polar region was often associated with less sea ice cover (White \& Peterson 1996) and therefore good food accessibility for offshore foragers. Second, higher SST in the study area can be caused by upwelling of circumpolar deep water in the western Antarctic Peninsula region (Jacobs \& Comiso 1997, Smith et al. 1999). The nutrient-rich water masses replenish surface waters with nutrients and hence are assumed to trigger plankton production (Prézèlin et al. 2000, 2004). The main prey of SPS are the pelagic fish species Electrona antarctica and Pleuragramma antarcticum (K. Reinhardt unpubl. data). Both fish species are zooplankton feeders (DeWitt \& Hopkins 1977). An upwelling of circumpolar deep water and hence increase of zooplankton, could be associated with higher abundance of these fish species. The time scale of such an hypothesised cascade from upwelling via enhanced primary production and zooplankton abundance, to increased fish abundance and food availability for top predators is not known. Moreover, the fish preyed upon by SPS are usually 3 to
6 yr old (K. Reinhardt unpubl. data). Their abundance in the skua foraging area is more likely the result of migration rather than local breeding, but relevant data are not yet available. Hence, a link between SST and fish availability remains speculative, but should be considered in future studies.

\section{Chick growth and breeding success}

Annual differences in food availability often lead to different chick growth rates, since the amount of food provided by the parents is an important condition for offspring growth in non-precocial birds. Generally, skuas prefer easily available terrestrial food; foraging in feeding territories within seabird colonies occurrs frequently (e.g. Pietz 1987, Hahn \& Peter 2003) and can enhance offspring growth (Votier et al. 2004, S. Hahn unpubl. data). We found an almost uniform chick growth pattern in terrestrially feeding BS benefiting from an always available resource. Additionally, offspring development of MSP and SPS pairs varied greatly between years. Hence, chicks of offshoreforaging parents (SPS and partly MSP) were subjected to annually variable and unpredictable marine resources. Further support comes from the speciesspecific susceptibility to climate conditions: growth of BS offspring was independent of climatic conditions compared to that of in MSP and SPS chicks, which was affected by sea surface temperature, sea ice cover, local temperature and wind (Ainley et al. 1990, Ritz et al. 2005). This was particularly obvious in the early chick stage and (to a lesser degree) in the middle chick stage. The decreasing sensitivity of older chicks to ambient conditions might arise from a generally enhanced ability to cope with adverse conditions, but also through higher survival probabilities of chicks from high-quality parents (Hahn \& Peter 2003). However, an additional reason might be the period and frequency of absence of the parents from the nest: BS fed in adjacent seabird colonies or from food washed ashore, SPS foraged offshore (Reinhardt 1997). Foraging trip lengths thus differed markedly, with short trips for BS and longer trips of several hours for SPS (Pietz 1986). SPS have to deal with variations in fish availability and accessibility due to sea ice cover (Young 1994), strengthened by bad weather conditions such as heavy storms, which make fishing difficult (Finney et al. 1999). In the absence of their parents, young chicks are exposed to chilling and starvation; more importantly, they have no protection against predation.

The general breeding success of BS declined over our study period, while that of MSP and SPS showed no such trend. Whether the decline in BS was caused by natural factors cannot yet be answered, since it par- 
alleled the banning of open garbage dumps since 1996, a former plentiful food source for skuas (Reinhardt 1997). Additionally, short-term fluctuations with a 3 to 5 yr frequency are common in Antarctic seabirds (Jenouvrier et al. 2005) and were possibly not detectable within our study period. More importantly, BS were able to raise offspring in all years, whereas the breeding success of MSP and SPS varied greatly between years, with even complete breeding failure occurring (Ritz et al. 2006). Hence, SPS and MSP again were more susceptible to changes in environmental conditions than BS. Taking into account the variety of factors that differentially affect reproduction parameters, it is not surprising that no single factor determined breeding success in the skua forms. Only pooling of the data revealed a positive effect of high ambient temperature in the pre-breeding period indicating suitable spring conditions and a general negative effect of sea ice cover for chick growth. The positive effect of wind speed on successful breeding is probably explained by frequent westerly winds which ensure plankton drift through the Bransfield Strait and thus food availability for zooplankton feeders.

\section{CONCLUSIONS}

Antarctic skuas showed annual variation in reproduction parameters depending on skua form and breeding stage, with smallest variation in egg size and large variation in hatching dates and offspring growth performance. Since up to $40 \%$ of the variation could be explained by abiotic factors, the larger part is probably attributable to biological parameters like parental age, quality, or foraging skills. However, we verified a 2-fold dependence of skua reproduction on the Antarctic environment: (1) all skuas were more affected by oceanographic conditions, i.e. SST and sea ice, than by weather conditions, but the magnitude of impact varied between skua forms, with SPS being more influenced than BS, and MSP being intermediately influenced. (2) Reproduction parameters of the early breeding season were strongly affected by oceanographic factors, whereas later in offspring development the importance of local weather conditions, especially wind, increased. These findings imply contrasting effects of potential future climate change: a further increase in air temperatures together with earlier snowmelt and shortening of ice cover period will lead to more suitable conditions for foraging during the pre-breeding period and facilitate an earlier onset of breeding for all skuas. However, the expected higher frequency of adverse-weather periods (Turner et al. 1997) could lead to worsening conditions for chick growth. Our results suggest that the effect of future cli- mate change on skuas in the maritime Antarctic will be more strongly mediated by changes in the marine food chain caused by sea ice cover (e.g. Loeb et al. 1997, Smith et al. 1999) and sea surface temperature alterations (Prézèlin et al. 2000) than by local weather conditions.

Acknowledgements. We thank T. Nadler, I. Prieto and D. Gladbach for additional field data. Additionally, we thank 3 anonymous referees and S. Bauer for constructive comments, which improved the manuscript greatly. The authors were supported by the Academy of Sciences of the G.D.R. (1984 to 1988), by the German Research Council (1994 to 2004: DFG Pe 454), by grants of the State of Thuringia (Landesgraduiertenstipendium) to S.H. and K.R. and the Instituto Antártico Argentino (D.M.). This is publication 3901 of the Netherlands Institute of Ecology (NIOO-KNAW).

\section{LITERATURE CITED}

Ainley DG, Ribic CA, Wood RC (1990) A demographic study of the south polar skua Catharacta maccormicki at Cape Crozier (Ross Island, Antarctica). J Anim Ecol 59:1-20

Ainley DG, Jacobs SS, Ribic CA, Gaffney I (1998) Seabird distribution and oceanic features of the Amundsen and southern Bellingshausen Seas. Antarct Sci 10:111-123

Barbraud C, Weimerskirch H (2001) Contrasting effects of the extent of sea-ice on the breeding performance of an Antarctic top predator, the snow petrel Pagodroma nivea. J Avian Biol 32:297-302

Burton RW (1968) Breeding biology of the brown skua, Catharacta skua lönnbergi (Mathews), at Signy Island, South Orkney Islands. Br Antarct Surv Bull 15:9-28

Busser C, Kahles A, Quillfeldt P (2004) Breeding success and chick provisioning in Wilson's storm-petrels Oceanites oceanicus over seven years: frequent failures due to food shortage and entombment. Polar Biol 27:613-622

Catry P, Furness RW (1997) Egg volume and within-clutch asymmetry in great skuas: are they related to adult quality? Colon Waterbirds 20:399-405

Coulson JC (1963) Egg size and shape in the kittiwake (Rissa tridactyla) and their use in estimating age composition of populations. Proc R Soc Lond B 140:211-227

DeWitt HH, Hopkins TL (1977) Aspects of the diet of the Antarctic silverfish, Pleuragramma antarcticum. In: Llano GA (ed) Adaptation within Antarctic ecosystems. Smithsonian Institution, Washington, DC, p 557-567

Finney SK, Wanless S, Harris MP (1999) The effect of weather conditions on the feeding behaviour of a diving bird, the common guillemot Uria aalge. J Avian Biol 30:23-30

Fraser WR, Hofmann EE (2003) A predator's perspective on causal links between climate change, physical forcing and ecosystem response. Mar Ecol Prog Ser 265:1-15

Graham MH (2003) Confronting multicollinearity in ecological multiple regression. Ecology 84:2809-2815

Guinet C, Chastel O, Koudil M, Durbec JP, Jouventin P (1998) Effects of warm sea-surface temperature anomalies on the blue petrel at the Kerguelen Islands. Proc R Soc Lond B 265:1001-1006

Hahn S, Peter HU (2003) Feeding territoriality and the reproductive consequences in brown skuas Catharacta antarctica lonnbergi. Polar Biol 26:552-559

Hahn S, Ritz MS, Peter HU (2003) Living in mixed pairs — better for fitness? A study in skuas. In: Huiskes AHL, Gieskes 
WWC, Rozema J, Schorno RML, van der Vies SM, Wolff WJ (eds) Antarctic biology in a global context. Bachhuys Publishers, Leiden, p 229-233

Hempel G, Kerry KR (1990) Antarctic ecosystems. SpringerVerlag, Berlin

Hiom L, Bolton M, Monaghan P, Worrall D (1991) Experimental evidence for food limitation of egg production in gulls. Ornis Scand 22:94-97

Jacobs SS, Comiso JC (1997) Climate variability in the Amundsen and Bellingshausen Seas. J Climatol 10: 697-709

Jenouvrier S, Barbraud C, Weimerskirch H (2003) Effects of climate variability on the temporal population dynamics of southern fulmars. J Anim Ecol 72:576-587

Jenouvrier S, Weimerskirch $\mathrm{H}$, Barbraud C, Park YH, Cazelles B (2005) Evidence of a shift in the cyclicity of Antarctic seabird dynamics linked to climate. Proc R Soc Lond B 272:887-895

Klaassen M (2003) Relationships between migration and breeding strategies in arctic breeding birds. In: Berthold P, Gwinner E, Sonnenschein E (eds) Avian migration. Springer-Verlag, Berlin, p 237-249

Loeb V, Siegel V, HolmHansen O, Hewitt R, Fraser W, Trivelpiece W, Trivelpiece S (1997) Effects of sea-ice extent and krill or salp dominance on the Antarctic food web. Nature 387:897-900

Moline MA, Claustre H, Frazer TK, Schofield O, Vernet M (2004) Alteration of the food web along the Antarctic Peninsula in response to a regional warming trend. Glob Change Biol 10:1973-1980

Phillips RA, Phalan B, Forster IP (2004) Diet and long-term changes in population size and productivity of brown skuas Catharacta antarctica lonnbergi at Bird Island, South Georgia. Polar Biol 27:555-561

Pietz PJ (1986) Daily activity patterns of south polar skua and brown skua near Palmer Station, Antarctica. Auk 103: 726-736

Pietz PJ (1987) Feeding and nesting ecology of sympatric south polar and brown skuas. Auk 104:617-627

Prézèlin BB, Hofmann EE, Klinck JM, Mengelt C (2000) The linkage between Upper Circumpolar Deep Water (UCDW) and phytoplankton assemblages on the west Antarctic Peninsula Continental Shelf. J Mar Res 58:165-202

Prézèlin BB, Hofmann EE, Moline M, Klinck JM (2004) Physical forcing of phytoplankton community structure and primary production in continental shelf waters of the Western Antarctic Peninsula. J Mar Res 62:419-460

Price T, Kirkpatrick M, Arnold SJ (1988) Directional selection

Editorial responsibility: Otto Kinne (Editor-in-Chief), Oldendorf/Luhe, Germany and the evolution of breeding date in birds. Science 240: 798-799

Ratcliffe N, Furness RW, Hamer KC (1998) The interactive effects of age and food supply on the breeding ecology of great skuas. J Anim Ecol 67:853-862

Reinhardt K (1997) Nahrung und Fütterung antarktischer Raubmöwen Catharacta antarctica lonnbergi und C. maccormicki. J Ornithol 138:199-213

Ritz MS, Hahn S, Peter HU (2005) Factors affecting chick growth in the south polar skua (Catharacta maccormicki): food supply, weather and hatching date. Polar Biol 29: $53-60$

Ritz MS, Hahn S, Janicke T, Peter HU (2006) Hybridisation between south polar skua (Catharacta maccormicki) and brown skua (C. antarctica lonnbergi) in the Antarctic Peninsula region. Polar Biol 29:153-159

Robbins CT (1981) Estimation of the relative protein cost of reproduction in birds. Condor 83:177-179

Siegel V (2000) Krill (Euphausiacea) demography and variability in abundance and distribution. Can J Fish Aquat Sci 57:151-167

Siegel V, Loeb V (1995) Recruitment of Antarctic krill Euphausia superba and possible causes for its variability. Mar Ecol Prog Ser 123:45-56

Smith RC, Ainley D, Baker K, Domack E and 7 others (1999) Marine ecosystem sensitivity to climate change. BioScience 49:393-404

Smith RC, Stammerjohn SE (2001) Variations of surface air temperature and sea-ice extent in the western Antarctic Peninsula region. Ann Glaciol 33:493-500

Turner J, Colwell SR, Harangozo SA (1997) Variability of precipitation over the coastal western Antarctic Peninsula from synoptic observations. J Geophys Res 102: 13999-14007

Vaughan DG, Marshall GJ, Connolley WM, Parkinson C and 5 others (2003) Recent rapid regional climate warming on the Antarctic Peninsula. Clim Change 60:243-274

Votier SC, Bearhop S, Ratcliffe N, Furness RW (2004) Reproductive consequences for great skuas specializing as seabird predators. Condor 106:275-287

Weimerskirch H, Inchausti P, Guinet C, Barbraud C (2003) Trends in bird and seal populations as indicators of a system shift in the Southern Ocean. Antarct Sci 15:246-256

White W, Peterson R (1996) An Antarctic circumpolar wave in surface pressure, wind, temperature and sea-ice extent. Nature 380:699-702

Young EC (1994) Skua and penguin, predator and prey. Cambridge University Press, Cambridge

Submitted: December 9, 2005; Accepted: August 10, 2006

Proofs received from author(s): March 5, 2007 